\title{
La visión del desarrollo dentro del contexto global y regional. El regionalismo a través de la Alianza del Pacífico y la Asociación Latinoamericana de Integración 2005-2014
}

\author{
Marcela Maldonado Bodart* \\ SANTOS LÓPEZ LEYVA**
}

Archivo recibido: 25 de mayo de 2016

Archivo aprobado: 14 de noviembre de 2016

Doi: http://10.12804/revistas.urosario.edu.co/desafios/a.4902

* Doctora en Estudios del Desarrollo Global, con mención honorífica y premio al mérito escolar, por la Universidad Autónoma de Baja California (UABC). Actualmente es profesorainvestigadora de Tiempo Completo en la Facultad de Ciencias Sociales y Políticas, UABC, campus Mexicali, Baja California. Es miembro del cuerpo académico de Estudios del Desarrollo Global y miembro fundador de la Red de Relaciones Internacionales y Desarrollo Global. Desde 2011, pertenece al Sistema Nacional de Investigadores (SNI) de CONACYT en México Nivel 1, además de contar con Reconocimiento de Profesor con Perfil Deseable del PRODEP. Entre sus principales líneas de investigación están los organismos internacionales, cooperación internacional, estudios regionales y globales y políticas públicas para el desarrollo. Correo electrónico: bodart@uabc.edu.mx. ORCID: http://orcid.org/0000-0001-7218-1590

** Doctor en Economía por la Universidad Nacional Autónoma de México. Posdoctorado en el Center for the Study of Higher Education de la Universidad de Arizona. En su labor académica destacan 108 publicaciones. En 2011 recibió el Premio Estatal de Ciencia y Tecnología, que otorga el Gobierno del Estado de Sinaloa. Fue nombrado Profesionista del Año por las Asociaciones de Profesionales de Culiacán. Recibió la Medalla Eustaquio Buelna y El Granito de Oro en su pueblo natal, Mocorito, Sinaloa. Forma parte del Sistema Nacional de Investigadores (SNI), CONACYT, México desde 1998. Actualmente es reconocido con el Nivel III en el SNI, CONACYT. Desde 2009 es profesor-investigador de la Facultad de Economía y Relaciones Internacionales de la Universidad Autónoma de Baja California, campus Tijuana, Baja California. Es responsable del cuerpo académico de Estudios del Desarrollo Global y Responsable y miembro fundador de la Red de Relaciones Internacionales y Desarrollo Global. Correo electrónico: sanlop1947@gmail.com. ORCID: http://orcid.org/0000-0002-8463-4718 
Para citar este artículo: Maldonado Bodart, M., \& López Leyva, S. (2017). La visión del desarrollo dentro del contexto global y regional. El regionalismo a través de la Alianza del Pacífico y la Asociación Latinoamericana de Integración 2005-2014. Desafios, 29(1), 13-49. Doi: http://10.12804/revistas.urosario.edu.co/desafios/a.4902

\title{
Resumen
}

Históricamente han existido distintos debates para alcanzar el desarrollo, desde diferentes ámbitos y espacios. La visión del desarrollo desde el espacio global, ha tenido una importante evolución hasta nuestros días, principalmente después de la II Guerra Mundial, a través de la Cooperación Internacional para el Desarrollo (CID). Desde el espacio regional, los mecanismos de cooperación económica han reflejado ser dinámicos y positivos para el desarrollo. Por ello, el presente trabajo pretende en primera instancia, realizar una revisión de la evolución sobre la visión de desarrollo desde un contexto global y regional. En una segunda fase, busca analizar las aportaciones comerciales, desde una visión del desarrollo regional, por medio de un análisis comparativo de la Alianza del Pacifico (AP) con respecto a la región y a la Asociación Latinoamericana de Integración (ALADI) para el periodo 2005 2014, como mecanismos de cooperación económica en América Latina y el Caribe $(A L y C)$ que buscan un desarrollo dentro de la misma región.

Palabras clave: Cooperación Internacional para el Desarrollo (CID), Alianza del Pacifico (AP), Asociación Latinoamericana de Integración (ALADI), Mecanismos de Cooperación Económica, América Latina y el Caribe (ALyC).

\section{The Vision of Development within a Global and Regional Context. Regionalism in the Pacific Alliance and the Latin American Integration Association, 2005-2014}

\begin{abstract}
Historically there have been various discussions on how to achieve development from different scopes and spaces. The vision of development from a global space has undergone a significant evolution to the present day, in particular after World War II, in the context of international development cooperation. Within a regional space, economic cooperation mechanisms have shown to be dynamic and positive for development. This paper aims, firstly,
\end{abstract}


to set forth a review of the evolution of the development vision from a global and regional perspective. Secondly, to analyze contributions in commerce from a regional development perspective through a comparative analysis of the Pacific Alliance and the Latin American Integration Association between 2005 and 2014, as economic cooperation mechanisms in Latin America and the Caribbean that seek development within the same region.

Keywords: International Development Cooperation, Pacific Alliance, Latin American Integration Association, economic cooperation mechanisms, Latin America and the Caribbean.

\title{
A visão do desenvolvimento dentro do contexto global e regional. O regionalismo através da Aliança do Pacífico e a Associação Latino- Americana de Integração 2005-2014
}

\begin{abstract}
Resumo
Historicamente têm existido diferentes debates para alcançar o desenvolvimento, desde diferentes âmbitos e espaços. A visão do desenvolvimento desde o espaço global, tem tido uma importante evolução até nossos dias, principalmente depois da II Guerra Mundial, através da Cooperação Internacional para o Desenvolvimento (CID). Desde o espaço regional, os mecanismos de cooperação económica têm refletido ser dinâmicos e positivos para o desenvolvimento. Por isso, o presente trabalho pretende em primeira instância, realizar uma revisão da evolução sobre a visão de desenvolvimento desde um contexto global e regional. Em uma segunda fase, busca analisar as contribuições comerciais, desde uma visão do desenvolvimento regional, e a Associação Latino-Americana de Integração (AL ADI) para o período 2005-2014, como mecanismos de cooperação económica na América Latina e o Caribe (ALyC) que buscam um desenvolvimento dentro da mesma região.

Palavras-chave: Cooperação Internacional para o Desenvolvimento (CID), Aliança do Pacífico (AP), Associação Latino-Americana de Integração (ALADI), Mecanismos de Cooperação Económica, América Latina e o Caribe (ALyC).
\end{abstract}

\section{Introducción}

Con el fin de la II Guerra Mundial, se establecieron las bases para la arquitectura actual de la Cooperación Internacional para el Desarrollo 
(CID), con el origen de los organismos internacionales como principales promotores de la búsqueda del desarrollo a nivel internacional. El surgimiento de nuevos Estados dentro del sistema internacional y el incremento de la desigualdad entre los países del Norte y los países del Sur, entre otros, llevó a nuevas problemáticas y retos para enfrentar el desarrollo desde distintas escalas y niveles. Con el inicio de la globalización surgió un incremento en las interconexiones a nivel global, principalmente en el aspecto comercial y económico, y con ello una desterritorialización de la política, lo que impulsó un crecimiento de redes de interdependencia entre distintos actores, en distintos ámbitos y espacios.

Frente a este nuevo escenario de interdepencia, el desarrollo se ha presentado en forma asimétrica en las distintas regiones y Estados; por esta razón, ha sido necesario buscar nuevas estrategias, esquemas y mecanismos de cooperación que permitan lograr un mayor desarrollo, siendo el espacio regional uno de oportunidad para alcanzarlo.

En este contexto, la región de América Latina y el Caribe (ALyC), a pesar de sus múltiples esfuerzos y esquemas de cooperación económica y comercial para alcanzar un mejor desarrollo desde 1960, aún cuenta con altos niveles de pobreza; según el OECD, 184 millones de personas viven en condiciones de pobreza, lo que representa el $28 \%$ de la población total de América Latina (2016, p. 17).

Por lo anterior, el presente trabajo tiene como objetivo principal realizar un análisis de la evolución en las perspectivas del desarrollo, primero desde el ámbito global, para después entender la lógica regional, a través de los mecanismos de cooperación económica y comercial como lo son la Alianza del Pacífico (AP) y la Asociaciación Latinoamericana de Integración (ALADI), a través de sus transacciones comerciales dentro del periodo 2005-2014.

Para ello, este artículo se desarrolla en cinco grandes apartados. El primero, detalla la evolución en la visión del desarrollo, desde un contexto global, destacando las principales acciones internacionales y los indicadores que detonaron en la medición y aplicación de políticas 
para el desarrollo a nivel global. En el segundo, se realiza una revisón conceptual, de lo que se entiende por región y sus características para identificar las variables, que se debate, pueden generar un desarrollo desde un nivel regional. En el tercer apartado, se destacan de manera general las distintas etapas del regionalismo que caracterizaron a la región de ALyC. El cuarto apartado señala la metodología del trabajo y el quinto comprende el análisis y los principales resultados que se obtuvieron a través de un análisis comparativo de las bases de datos del Banco Mundial (2016a y 2016b), para el periodo de 2005 al 2014, de las importaciones, exportaciones y los saldos de la balanza comercial, para cada uno de los países que integran la AP, la ALADI, y de ALyC, para con ello determinar su aporte en términos comerciales, frente a la región de ALyC. Asimismo, se comparan los datos con el total mundial de exportaciones e importaciones para el periodo comprendido entre 2005-2014. Finalmente se presenta una caracterización de la red de relaciones económicas comerciales que sostienen cada uno de los países que pertenecen a la AP y la ALADI, utilizando como herramienta el software UCINET 6.

\section{Perspectivas del Desarrollo: el contexto global}

A través de distintas épocas se han planteado diferentes visiones para alcanzar el desarrollo, y se han implementado múltiples estrategias para reducir la pobreza y el hambre, aumentar el crecimiento económico y enfrentar crisis financieras, entre otros problemas del desarrollo. Estas problemáticas han llevado al Estado, a lo largo de las últimas décadas, a la implementación de una serie de políticas, en su búsqueda hacia un mejor nivel de desarrollo.

El régimen internacional de la cooperación para el desarrollo, establece sus bases y dinámicas actuales al finalizar la II Guerra Mundial, a través de los principales organismos internacionales, que surgieron como resultado de la permanente búsqueda de la paz, seguridad y del desarrollo, y que aún permanecen vigentes. La importancia en la búsqueda de la Cooperación para el Desarrollo es institucionalizada desde sus inicios a través del Sistema de Naciones Unidas (UN), el Banco Mundial 
(BM), el Fondo Monetario Internacional (FMI) y la Organización para la Cooperación y el Desarrollo Económicos (OCDE), principalmente, en donde la visión del desarrollo es un eje fundamental para llevar a cabo la cooperación internacional. Weiss, Forsythe y Coate (2004), señalan que Kenneth Dadzie, uno de los principales observadores en el análisis del Sistema de Naciones Unidas, distingue principalmente cuatro grandes fases, en las que se ha identificado una evolución en la visión del desarrollo desde el ámbito internacional.

Fase 1. Estado nacional capitalista (1945-1962). En este periodo, la principal tarea y visión del desarrollo, desde el Sistema de Naciones Unidas, fue que el Estado consiguiera el crecimiento económico nacional por medio del clásico capitalismo estatal (Weiss et al., 2004). Por otra parte, durante los años cincuenta, los organismos internacionales para el desarrollo se fueron consolidando, a través del propio Sistema de Naciones Unidas, BM, FMI, la creación de bancos regionales para el desarrollo, así como de las comisiones económicas regionales de las Naciones Unidas, estableciéndose las bases de una infraestructura internacional para alcanzar el desarrollo. Paralelamente, los procesos de descolonización avanzaban, surgiendo nuevos Estados independientes que exigían nuevas demandas.

En este mismo periodo, ya dentro del contexto de la Guerra Fría, Bremer (2010) señala que surge el concepto de Tercer Mundo y explica que se inicia una búsqueda de nuevas opciones políticas y económicas, que terminan en el surgimiento de respuestas como el Movimiento de los No Alineados (NAM, por sus siglas en inglés), fundado en 1955 y conformado en su mayoría por ex-colonias. En 1961, ya con el surgimiento de la OCDE, se crea el Comité de Ayuda para el Desarrollo (CAD). El Comité, conformado por Estados, se encarga de gestionar y financiar programas de cooperación para el desarrollo, dependiendo del nivel de desarrollo en el que se encuentre el Estado receptor de la ayuda, mientras que el BM, el FMI y el PNUD participan como observadores (OECD, 2016b).

Asimismo, Weiss, Forsythe y Coate (2004), señalan que en esta fase, el desarrollo fue pensado primordialmente en términos del crecimiento del 
Estado nacional; sin embargo, más allá de la idea de alentar a los Estados a tomar sus decisiones bajo la visión del liberalismo económico y del capitalismo estatal para alcanzar un crecimiento económico, estaba la visión de la teoría funcionalista para alcanzar el desarrollo. En este periodo, el interés se centró en las problemáticas del desarrollo relacionadas con temas como la pobreza, la desnutrición, la expansión demográfica, etc. (Bremer, 2010).

Fase 2. Acción afirmativa internacional (1962-1981). A principios de 1962, la actividad para el desarrollo, que de manera oficial se realizaba dentro de los principales órganos de las Naciones Unidas, se enfocó de manera persistente en las desigualdades del ingreso entre los países ricos del Norte y los países pobres del Sur, es decir, entre los países desarrollados y los países en desarrollo (Weiss et al., 2004). A mediados de los años sesenta, Maira (1997) destaca que surge el Grupo de los 77, conformado por países en desarrollo que tenían demandas y problemáticas comunes dentro del seno del Sistema de Naciones Unidas, como una forma de realizar coaliciones a favor de promover sus intereses comunes.

$\mathrm{Al}$ respecto, Weiss et al. (2004) señalan que los movimientos de descolonización dieron origen a una 'avalancha' de nuevos Estados independientes, por lo que para 1961 la membresía en las Naciones Unidas se duplicó a 104 países, de 51 miembros originales en 1945. En 1964, surge la Conferencia de Naciones Unidas para el Comercio y Desarrollo (UNCTAD, por sus siglas en inglés), dando un giro a la reorientación en la visión para el desarrollo, y en 1966, el Programa de Naciones Unidas para el Desarrollo (PNUD), teniendo como encomienda la reducción de la pobreza, la creación de empleos y la protección del medio ambiente a nivel internacional (UNDP, 2016), convirtiéndose en uno de los programas clave para el desarrollo a nivel internacional dentro del Sistema de Naciones Unidas. En los años setenta, se publica el informe Pearson, en el que se propone una nueva base para la cooperación internacional, una reformulación del concepto de desarrollo y la consideración fundamental de reforzar la Ayuda Oficial para el Desarrollo (AOD), recomendando la aportación 
del $0.7 \%$ del Producto Nacional Bruto, para la CID, que se considera todavía en la actualidad (Álvarez, 2012).

Asimismo, el BM comienza a utilizar el Proyect Cycle Management como herramienta de administración, pues los proyectos constituyen el único formato para la entrega de ayuda para los Estados. Asimismo, se difunde el uso del enfoque de marco lógico, ampliamente utilizado hasta el día de hoy (Álvarez, 2012).

Cabe destacar que en esta fase, Weiss, Forsythe y Coate (2004), señalan que hay una reorientación de la visión del desarrollo, en donde la naturaleza automática de este, concebida a través de la visión del liberalismo económico nacional fue repensada tanto dentro del seno de las Naciones Unidas, como dentro del BM, teniendo como orígenes el pensamiento de Raúl Prebisch y sus colegas de la Comisión Económica para América Latina (CEPAL).

Fase 3. Regreso del Neoliberalismo (1981-1989). Durante la década de los ochenta, las políticas comienzan a enfocarse hacia los aspectos macroeconómicos y diferentes temas sociales y ambientales. Ante esto, las políticas globales de cooperación para el desarrollo de los organismos internacionales, presentaban un enfoque de desarrollo de cambio estructural o fundamental, que de acuerdo a Gasper (2005), se dió a través del uso más neutral y no evolutivo del concepto, y que se utilizó con el objetivo de analizar el desarrollo en términos de Producto Interno Bruto (PIB) per cápita.

El pensamiento económico y el desarrollo político de Occidente, a través de figuras como Margaret Thatcher en Gran Bretaña y Ronald Reagan en los Estados Unidos, llevó a cambios en la visión de la política exterior desde la esfera económica (Weiss Forsythe \& Coate, 2004). Por otra parte, las instituciones de Bretton Woods comenzaron a sentir descontento con la visión para el desarrollo prevaleciente, debido a una ausencia de rápido progreso económico en muchos de los países en desarrollo. En este sentido, comenzaron a implementar programas de ajuste estructural condicionando sus préstamos (Weiss Forsythe \& Coate, 2004). 
Así, con las reformas estructurales propuestas en 1989, por medio del Consenso de Washington, se inició la búsqueda de un modelo abierto, de liberalización comercial y de mercado de capitales, entre otros, dirigido en un principio hacia los países de América Latina, pero que posteriormente se observaría en el resto de las regiones. Este condicionó el financiamiento por parte de los organismos internacionales, como el BM o el FMI, con el cumplimiento de las reformas conocidas como programas de ajuste estructural (Observatorio de Multinacionales en América Latina, 2012). En esta fase, también se destaca que, contrario a las predicciones del grupo de Prebisch, un número de Estados Asiáticos, conocidos como los "Tigres Asiáticos", comenzaron a tener ganancias económicas rápidamente, principalmente a través de las transacciones comerciales, entre otras políticas (Weiss Forsythe \& Coate, 2004). Finalmente, la fase termina con la caída del Muro de Beríln y el fin de la Guerra Fría.

Fase 4. Desarrollo Humano Sostenible (1989-2015). En esta fase se destaca un proceso de transición de las economías del régimen socialista a economías de libre mercado, entre otros nuevos retos que requerían de nuevas estrategias y políticas dentro de los organismos internacionales. Con el fin de la visión de un mundo bipolar y el inicio de la globalización, se adopta una visión más amplia del desarrollo, desde distintos enfoques que marcarían su influencia tanto en las políticas globales de cooperación para el desarrollo, como en las agendas a nivel internacional, estatal y local; dichos enfoques principalmente basan su visión en las capacidades y la evaluación, reflejándose el desarrollo ya sea como una mejora o un buen resultado. Los enfoques de esta etapa principalmente son: el Índice de Desarrollo Humano (IDH), los Objetivos del Desarrollo del Milenio (ODM) y los Objetivos del Desarrollo Sostenible (ODS), establecidos en septiembre de 2015.

La visión del desarrollo que establece el enfoque del el Programa de Naciones Unidas para el Desarrollo (PNUD), es el denominado Índice de Desarrollo Humano (IDH), el cual no solo evalúa el bienestar económico para medir el desarrollo, sino que la salud y la educación son imprescindibles en el proceso, evolucionando el enfoque del 
desarrollo hacia las personas y sus capacidades, así como el uso que hacen de las mismas (Álvarez, 2012). Dadzie señala que la cooperación económica internacional para el desarrollo entra en una fase de madurez, en la que "el desarrollo por sí mismo es cada vez más visto enfocado hacia las personas como un proceso equitativo, en donde la meta final debe ser el mejoramiento de la condición humana" (citado en Weiss et al., 2004, p. 235).

En 1994, a través del reporte "Una Agenda para el Desarrollo", el Secretario General del Sistema de Naciones Unidas, Boutros BoutrosGhali, declara al desarrollo como un derecho humano fundamental, presentando un marco en el que destaca la interdependencia que se da de manera natural entre la paz, la economía, la sociedad civil, la democracia, la justicia social y el medio ambiente, como componentes indispensables del proceso de desarrollo (Weiss et al., 2004).

El reto de la globalización ha sido una constante para los organismos internacionales aun en la actualidad, ya que las ventajas de las dinámicas globales se han presentado de forma asimétrica entre los distintos Estados y regiones. Reconociendo estas asimetrías, en septiembre del 2000 se celebra la Cumbre del Milenio de Naciones Unidas, en la que los países miembros de la organización aprueban la Declaración del Milenio, estableciéndose con ello ocho objetivos a nivel global para alcanzar el desarrollo, conocidos como Objetivos del Desarrollo del Milenio (ODM) y trazándose como fecha de cumplimiento el año 2015.

Inicialmente concebidos para ser alcanzados a nivel global, en el 2005 durante la Cumbre del Milenio +5 , se acordó modificar la cobertura geográfica de aplicación, para que trascendieran hacia una escala de país por país (Tezanos \& Martinez, 2010), y con ello se inicia la necesidad de replantear estrategias en las dinámicas y los procesos de las políticas al interior de cada uno de los Estados y regiones. A partir del establecimiento de los ODM, las políticas globales de cooperación para el desarrollo entraron en un proceso de redimensión y ajuste para la consecución de los ODM, a través de una serie de conferencias, foros, declaraciones, consensos y cumbres, mediante 
los cuales se fueron movilizando y fortaleciendo las actividades cooperativas entre los organismos internacionales, Estados, organismos no gubernamentales, organismos privados y de la sociedad civil en su conjunto.

Entre estos se pueden destacar la Conferencia Internacional sobre el Financiamiento para el Desarrollo, la Declaración de Roma, la Declaración de París, la Cumbre del Grupo de los Veinte (G-20), la Cuarta Conferencia de Países Menos Desarrollados, el Cuarto Foro de Alto Nivel sobre la Eficacia de la Ayuda, la Sexta Cumbre de las Américas, la Tercera Conferencia Internacional Financiamiento y Desarrollo, y la Agenda para el Desarrollo Sostenible. Las principales características que se pueden destacar de cada uno se presentan en el tabla 1.

Tabla 1. Principales foros y eventos internacionales para el desarrollo 2000-2015

\begin{tabular}{|c|c|c|}
\hline \multirow[t]{3}{*}{2000} & \multirow[t]{3}{*}{ Declaración del Milenio } & $\begin{array}{l}\text { Objetivos de Desarrollo Sostenible. } 8 \text { Objetivos: 1) } \\
\text { Erradicar la pobreza extrema y el hambre. } \\
\text { 2) Enseñanza primaria universal. 3) Promover la } \\
\text { igualdad de género y la autonomía de la mujer. 4) } \\
\text { Reducir la mortalidad infantil, 5) Mejorar salud } \\
\text { materna. 6) Combatir el VIH, el paludismo y otras } \\
\text { enfermedades. 7) Garantizar sostenibilidad del medio } \\
\text { ambiente. 8) Fomentar una asociación mundial para } \\
\text { el desarrollo. }\end{array}$ \\
\hline & & Redimensión y ajuste de políticas para la CID. \\
\hline & & $\begin{array}{l}\text { Fortalecimiento de las actividades de cooperación } \\
\text { entre: OI/Estados/ONG, organismos privados/ } \\
\text { sociedad civil. }\end{array}$ \\
\hline \multirow{4}{*}{2002} & \multirow{4}{*}{$\begin{array}{l}\text { Conferencia } \\
\text { Internacional de } \\
\text { Financiamiento para el } \\
\text { Desarrollo, Sistema de } \\
\text { Naciones Unidas }\end{array}$} & Consenso de Monterrey. \\
\hline & & $\begin{array}{l}\text { Se incluye la visión del comercio internacional como } \\
\text { promotor del desarrollo. }\end{array}$ \\
\hline & & $\begin{array}{l}\text { Importancia de incrementar la cooperación financiera } \\
\text { y técnica internacional para el desarrollo. }\end{array}$ \\
\hline & & $\begin{array}{l}\text { Reconoce la Importancia de que actores públicos y } \\
\text { privados requieren de la CID. Continúa }\end{array}$ \\
\hline
\end{tabular}




\begin{tabular}{|c|c|c|}
\hline \multirow[t]{2}{*}{2003} & \multirow[t]{2}{*}{ Declaración de Roma } & $\begin{array}{l}\text { Importancia de armonización de políticas, } \\
\text { procedimientos y prácticas operacionales para } \\
\text { incrementar la eficiencia de la AOD y contribuir a los } \\
\text { ODM. }\end{array}$ \\
\hline & & $\begin{array}{l}\text { Diseño de planes de acción por parte de donantes- } \\
\text { Armonización para la AOD. }\end{array}$ \\
\hline \multirow[b]{2}{*}{2005} & \multirow[b]{2}{*}{ Declaración de París } & $\begin{array}{l}\text { OCDE, Principios Clave para mejorar el proceso } \\
\text { CID. }\end{array}$ \\
\hline & & $\begin{array}{l}\text { 1) Ownership-Apropicación PD. } \\
\text { 2) Alignment-Estrategias alineadas entre los donantes } \\
\text { y receptores. } \\
\text { 3) Harmonisation-Coordinación de estrategias entre los } \\
\text { organismos que donan. } \\
\text { 4) Gestión por Resultados. } \\
\text { 5) Rendición de Cuentas Mutua. }\end{array}$ \\
\hline 2010 & Cumbre G-20 & $\begin{array}{l}\text { 1) Crecimiento incluyente, sostenible, flexible para } \\
\text { una reducción de la pobreza duradera y significativa } \\
\text { no solo con AOD, sino con otras fuentes de } \\
\text { financiamiento. }\end{array}$ \\
\hline \multirow{3}{*}{2011} & $\begin{array}{l}\text { Cuarta Conferencia } \\
\text { Países Menos } \\
\text { Desarrollados, } \\
\text { UNCTAD }\end{array}$ & $\begin{array}{l}\text { Se demandó una Arquitectura para el } \\
\text { Financiamiento, que apoyarara el desarrollo de sus } \\
\text { economías y permitiera liberarse eventualmente de la } \\
\text { dependencia de la ayuda. }\end{array}$ \\
\hline & \multirow{2}{*}{$\begin{array}{l}\text { Cuarto Foro de Alto } \\
\text { Nivel Eficacia de la } \\
\text { Ayuda, OCDE }\end{array}$} & $\begin{array}{l}\text { Se decide ampliar y profundizar la CID, involucrando } \\
\text { a los actores no estatales que deseen formar parte de } \\
\text { la agenda para el desarrollo. }\end{array}$ \\
\hline & & $\begin{array}{l}\text { Se reconoce la complejidad de la arquitectura para la } \\
\text { CID. }\end{array}$ \\
\hline 2012 & $\begin{array}{l}\text { Sexta Cumbre de las } \\
\text { Américas, "Conectando } \\
\text { las Américas", OEA }\end{array}$ & $\begin{array}{l}\text { Se destaca a la cooperación regional como medio } \\
\text { para alcanzar un mayor desarrollo y superación de } \\
\text { desafíos como la pobreza, la seguridad ciudadana, los } \\
\text { desastres, la desigualdad. }\end{array}$ \\
\hline
\end{tabular}

Continúa 


\begin{tabular}{|l|l|l|}
\hline \multirow{2}{*}{2015} & $\begin{array}{l}\text { Tercera Conferencia } \\
\text { Internacional } \\
\text { Financiamiento y } \\
\text { Desarrollo, Sistema } \\
\text { de Naciones Unidas, } \\
\text { Etiopía. }\end{array}$ & $\begin{array}{l}\text { Identificar y movilizar todas las fuentes de } \\
\text { financiamiento, públicas, privadas, nacionales e } \\
\text { internacionales, para promover el desarrollo: recursos } \\
\text { públicos nacionales, negocios privados, CID, comercio } \\
\text { internacional, deuda y sustentabilidad de la deuda, } \\
\text { sistémicas, ciencia, tecnología, innovación y la creación } \\
\text { de capacidades. }\end{array}$ \\
\cline { 2 - 3 } & $\begin{array}{l}\text { Agenda Desarrollo } \\
\text { Sostenible 2030, Sistema } \\
\text { Naciones Unidas }\end{array}$ & 17 Objetivos del Desarrollo Sostenible. \\
\hline
\end{tabular}

Fuente: elaboración propia con información de Álvarez (2012), Red Argentina para la Cooperación Internacional (2012) y UN (2016).

Con la nueva Agenda para el Desarrollo Sostenible 2030, se adoptan los 17 Objetivos del Desarrollo Sostenible (ODS) a nivel global, iniciándose una nueva fase de procesos de transición hacia una redimensión y replanteamiento en las políticas internacionales para el desarrollo, que implica cambios en procesos y dinámicas no solo para el Estado, sino ahora para la multiplicidad de actores y dimensiones que implica cada uno estos objetivos.

En América Latina, tan solo en el periodo de 2000-2014, se identifica una transición en el nivel de ingreso per cápita, y por lo tanto, en su clasificación. De acuerdo con la OCDE (2001, 2006, 2011 y 2016), los países se pueden clasificar conforme a su nivel de ingreso per cápita como países menos desarrollados, países de ingreso medio bajo y países de ingreso medio alto, a fin de establecer parte de los criterios para ser susceptible de ser beneficiados por algún tipo de AOD.

Tabla 2. Evolución en la clasificación de la OCDE para los países de América Latina y el Caribe, conforme a su Nivel de Ingreso per cápita 2000-2014 (dólares americanos).

\begin{tabular}{|l|l|l|c|}
\hline \multicolumn{1}{|c|}{ 2000-2004 } \\
\hline \multicolumn{1}{|c|}{ Clasificación } & \multicolumn{1}{|c|}{ Países América Latina y el Caribe } & $\begin{array}{r}\text { Total } \\
\text { ALyC }\end{array}$ & $\begin{array}{c}\text { Total } \\
\text { Mundial }\end{array}$ \\
\hline $\begin{array}{l}\text { Países Menos } \\
\text { Desarrollados }\end{array}$ & Haití. & 1 & 51 \\
\hline
\end{tabular}




\begin{tabular}{|c|c|c|c|}
\hline $\begin{array}{l}\text { Países de Ingreso } \\
\text { Bajo (menos de } \\
745 \text {, en 2001) }\end{array}$ & Nicaragua. & 1 & 22 \\
\hline $\begin{array}{l}\text { Países de Ingreso } \\
\text { Medio Bajo (746- } \\
2975 \text {, en 2001) }\end{array}$ & $\begin{array}{l}\text { Belice, Bolivia, Colombia, Cuba, República } \\
\text { Dominicana, El Salvador, Ecuador, } \\
\text { Guatemala, Guyana, Honduras, Jamaica, } \\
\text { Paraguay, Perú, San Vicente y las Granadinas, } \\
\text { Surinam. }\end{array}$ & 15 & 46 \\
\hline $\begin{array}{l}\text { Países de Ingreso } \\
\text { Medio Alto (2976- } \\
9205 \text {, en 2001) }\end{array}$ & $\begin{array}{l}\text { Brasil, Chile, Costa Rica, Dominica, Granada, } \\
\text { Panamá, Venezuela, Antigua y Barbuda, } \\
\text { Argentina, Barbados, México, Montserrat, San } \\
\text { Cristóbal y Nieves, Santa Lucia, Trinidad y } \\
\text { Tobago, Uruguay. }\end{array}$ & 16 & 33 \\
\hline Total & & & 152 \\
\hline \multicolumn{4}{|c|}{ 2005-2009 } \\
\hline $\begin{array}{l}\text { Países Menos } \\
\text { Desarrollados }\end{array}$ & Haití. & 1 & 49 \\
\hline $\begin{array}{l}\text { Países de Ingreso } \\
\text { Bajo (menos de } \\
935 \text {, en 2007) }\end{array}$ & NA & 0 & 12 \\
\hline $\begin{array}{l}\text { Países de Ingreso } \\
\text { Medio Bajo (936- } \\
3705 \text {, en 2007) }\end{array}$ & $\begin{array}{l}\text { Bolivia, Colombia, República Dominicana, } \\
\text { Ecuador, El Salvador, Guatemala, Guyana, } \\
\text { Honduras, Nicaragua, Panamá, Paraguay, Perú. }\end{array}$ & 11 & 48 \\
\hline $\begin{array}{l}\text { Países de Ingreso } \\
\text { Medio Alto (3706- } \\
\text { 11455, en 2007) }\end{array}$ & $\begin{array}{l}\text { Argentina, Belice, Barbados, Brasil, Chile, } \\
\text { Costa Rica, Cuba, Dominica, Granada, } \\
\text { Jamaica, México, Montserrat, Panamá, San } \\
\text { Cristóbal y Nieves, Santa Lucia, San Vicente y } \\
\text { las Granadinas, Surinam, Trinidad y Tobago, } \\
\text { Uruguay, Venezuela. }\end{array}$ & 20 & 43 \\
\hline Total & & 33 & 152 \\
\hline \multicolumn{4}{|c|}{ 2010-2014 } \\
\hline $\begin{array}{l}\text { Países Menos } \\
\text { Desarrollados }\end{array}$ & Haití. & 1 & 48 \\
\hline $\begin{array}{l}\text { Países de Ingreso } \\
\text { Bajo (menos de } \\
\text { 1045, en 2013) }\end{array}$ & NA & 0 & 4 \\
\hline
\end{tabular}




\begin{tabular}{|l|l|l|l|}
\hline $\begin{array}{l}\text { Países de Ingreso } \\
\text { Medio Bajo (1046- } \\
\text { 4125, en 2013) }\end{array}$ & $\begin{array}{l}\text { Bolivia, El Salvador, Guyana, Guatemala, } \\
\text { Honduras, Nicaragua, Paraguay. }\end{array}$ & 7 & 36 \\
\hline $\begin{array}{l}\text { Países de Ingreso } \\
\text { Medio Alto (4126- } \\
12745, \text { en 2013) }\end{array}$ & $\begin{array}{l}\text { Chile, Colombia, Costa Rica, Cuba, Dominica, } \\
\text { República Dominicana, Ecuador, Granada, } \\
\text { Jamaica, México, Montserrat, Panamá, Perú, } \\
\text { San Cristóbal y Nieves, Santa Lucia, San } \\
\text { Vicente y las Granadinas, Surinam, Uruguay, } \\
\text { Venezuela. }\end{array}$ & 23 & 49 \\
\hline Total & & 31 & 137 \\
\hline
\end{tabular}

Fuente: elaboración propia con datos de la OECD (2001, 2006, 2011 y 2016).

\section{Perspectivas del Desarrollo: el contexto del regionalismo}

Dentro del régimen económico internacional actual, la visión para alcanzar el desarrollo desde un ámbito regional surge después de la II Guerra Mundial, principalmente en los años cincuenta, a través de los mecanismos de cooperación establecidos dentro de la región europea. No es sino hasta finales de los años ochenta que resurge con mayor impacto, destacándose la importancia actual del regionalismo dentro de las dinámicas y procesos actuales de la globalización. En este sentido, entender los beneficios y la conceptualización de la región se ha convertido en un eje importante.

$\mathrm{Al}$ respecto, Hettne (2005) señala que el concepto de región es usado o conceptualizado de manera distinta dependiendo de la disciplina. En el campo de la Geografía, las regiones son usualmente vistas como entidades subnacionales o como provincias históricas, que transitaron hacia Naciones-Estado, aunque más recientemente son entendidas como unidades creadas. Sin embargo, en las Relaciones Internacionales, estas son frecuentemente entendidas como subsistemas supranacionales del sistema internacional. Asimismo, se destaca la importancia, si las regiones son vistas como subsistemas del sistema internacional o como solo rasgos característicos emergentes regionales con sus propias dinámicas. 
Hurrell (2007), señala cuatro puntos importantes a considerar para entender a las regiones: como un espacio contenedor de cultura y diversidad; como polos o poderes; como niveles que están dentro de un sistema multinivel de gobernanza global, y como precursoras de cambio en el carácter de la sociedad internacional.

De esta forma, entender las regiones como niveles que están dentro de un sistema multinivel de gobernanza a escala global implica que dentro de una región operan e interactúan una serie de actores, procesos y problemáticas, que generan distintos resultados dentro del propio nivel y en los distintos niveles o escalas.

Por ello, Coe, Hess, Yeung, Dicken y Henderson (2004) señalan a la región, en el sentido de espacios subnacionales, como focos de actividad económica, pues en éstos ocurren procesos sistémicos de rápidos cambios tecnológicos y mejor movilidad de capital, así como una competencia intraregional por la inversión, desde una perspectiva neoliberal.

Rojas (2013) distingue principalmente el componente geográfico, destacando con ello el componente de identidad como base para las dinámicas y procesos regionales conocidos como regionalismo, haciendo diferencia de la denominada regionalización, conocida como un área comprendida por varios Estados y con múltiples actores.

Así, de acuerdo con una visión más completa, Hettne (2005) señala que una región consiste en un conjunto de Estados que tienen lazos en común, ya sea étnicos, culturales, sociales, históricos o de idioma. Sin embargo, las regiones, aún más ampliamente, pueden ser diferenciadas en términos de cohesividad social, es decir, el conocimiento de una propia herencia o patrimonio, como cultural, de raza, idioma, historia o religión; cohesividad económica, como patrones comerciales y complementariedad económica; cohesividad política, como tipo de régimen político, ideología, y cohesividad organizacional, que se refiere a la existencia de instituciones regionales formales.

Así, desde la visión racional del regionalismo, Karns y Mingst (2004) enfatizan que los Estados dentro de un área geográfica pueden de 
una manera más rápida y efectiva enfrentar una serie de problemáticas comunes, ya que éstos están más cercanos, compartiendo además antecedentes y enfoques. Así, la mayoría de las definiciones del regionalismo asumen que los Estados participantes comparten proximidad geográfica y un grado de interdependencia mutua. En cuanto a las motivaciones para establecer acuerdos regionales, Tugores (2005) señala que son muy variadas; sin embargo, se pueden señalar principalmente las ganancias económicas y las comerciales, pero también están las políticas, que se asocian a un conjunto de relaciones e intereses económicos entre países. Asimismo, también influye la posibilidad de establecer un mecanismo para tratar problemas con una dimensión regional, como lo son los problemas ambientales, flujos migratorios, o los denominados por el BM, como lo son los "bienes públicos regionales".

A nivel internacional, Karns y Mingst (2004) identifican dos grandes oleadas del regionalismo durante los últimos 50 años. La primera, en donde se establecieron las primeras fases de la integración europea en los años sesenta. En esta oleada, muchos países en otras partes del mundo intentaron imitar, en muchos casos sin éxito, el esquema europeo, iniciando esquemas de integración económica. El interés por el regionalismo y la integración se desvaneció a medida de que se percibieron pocos beneficios económicos, sumando la crisis de los años setenta, que condujo a muchos países a la adopción de políticas proteccionistas.

La segunda oleada del regionalismo comenzó a finales de los años ochenta, acompañada de los esfuerzos europeos por lograr un mercado único interno y del llamado "Nuevo Regionalismo" en América del Norte, reflejado en el Tratado de Libre Comercio de América del Norte (TLCAN). Entre los principales factores que estimularon al "Nuevo Regionalismo", se pueden destacar los cambios económicos globales, la transformación de la Unión Soviética y de Europa del Este, la incertidumbre sobre el resultado de la Ronda de Uruguay en relación con las negociaciones del comercio mundial, la preocupación sobre la emergencia de nuevos bloques comerciales, así como la búsqueda de nuevas formas de cooperación internacional. (Karns, Ampersand \& Mingst, 2004). 
Por su parte, Phillips (2003) destaca una redefinición del tipo de regionalismo que prevaleció en los años noventa, denominado "regionalismo abierto" de liberalización comercial. Gamble y Payne (citado en Phillips, 2003), señalan que la regionalización, así como la globalización, representa más bien una combinación de estructuras históricas y emergentes, que comprenden una compleja articulación entre instituciones y reglas ya establecidas, con nuevos y distintivos patrones de interacción social entre actores no estatales.

En este contexto, Tugores (2005) plantea que existe una dualidad entre el regionalismo abierto frente al regionalismo estratégico. Esto se debe a que en el primero, se origina principalmente una integración de forma natural, con bloques regionales que mantienen una política comercial exterior abierta, mientras que en el segundo, se da para obtener ganancias a expensas de otros.

Para Tugores (2005), también se distinguen principalmente dos oleadas de regionalismo. El primero, denominado "regionalismo de primera generación”, que se consolidó en los años sesenta, principalmente y de forma significativa en Europa Occidental, mientras que la segunda oleada, que inició en los años noventa, con la principal carácterística de ser más dinámica, y en la que Estados Unidos se incorpora a los procesos, a través de diversos acuerdos regionales.

Tabla 3. Olas de Regionalismo

\begin{tabular}{|c|c|}
\hline PRIMERA OLA & \\
\hline Bloque Soviético y Europeo & Latinoamérica \\
\hline OTAN & Organización de Estados Americanos (1948-) \\
\hline Unión Europea Occidental (1955-) & Tatado de Río (1947-) \\
\hline Pacto de Varsovia (1955-1991) & Mercado Común Centroamericano (1961-1991) \\
\hline Consejo de Europa (1948-) & Comunidad Andina (1969-) \\
\hline $\begin{array}{l}\text { Comunidad Europea del Carbón y el Acero } \\
\text { (1952-) }\end{array}$ & Comunidad del Caribe (1973-) \\
\hline Comunidad Europea de Energía Atómica (1958-) & $\begin{array}{l}\text { Asociación Latinoamericana de Libre } \\
\text { Comercio (1969-1980) }\end{array}$ \\
\hline $\begin{array}{l}\text { Comunidad Económica Europea (1958-) } \\
\text { Consejo de Asistencia Económica Mutua } \\
(1948-1991)\end{array}$ & \\
\hline
\end{tabular}




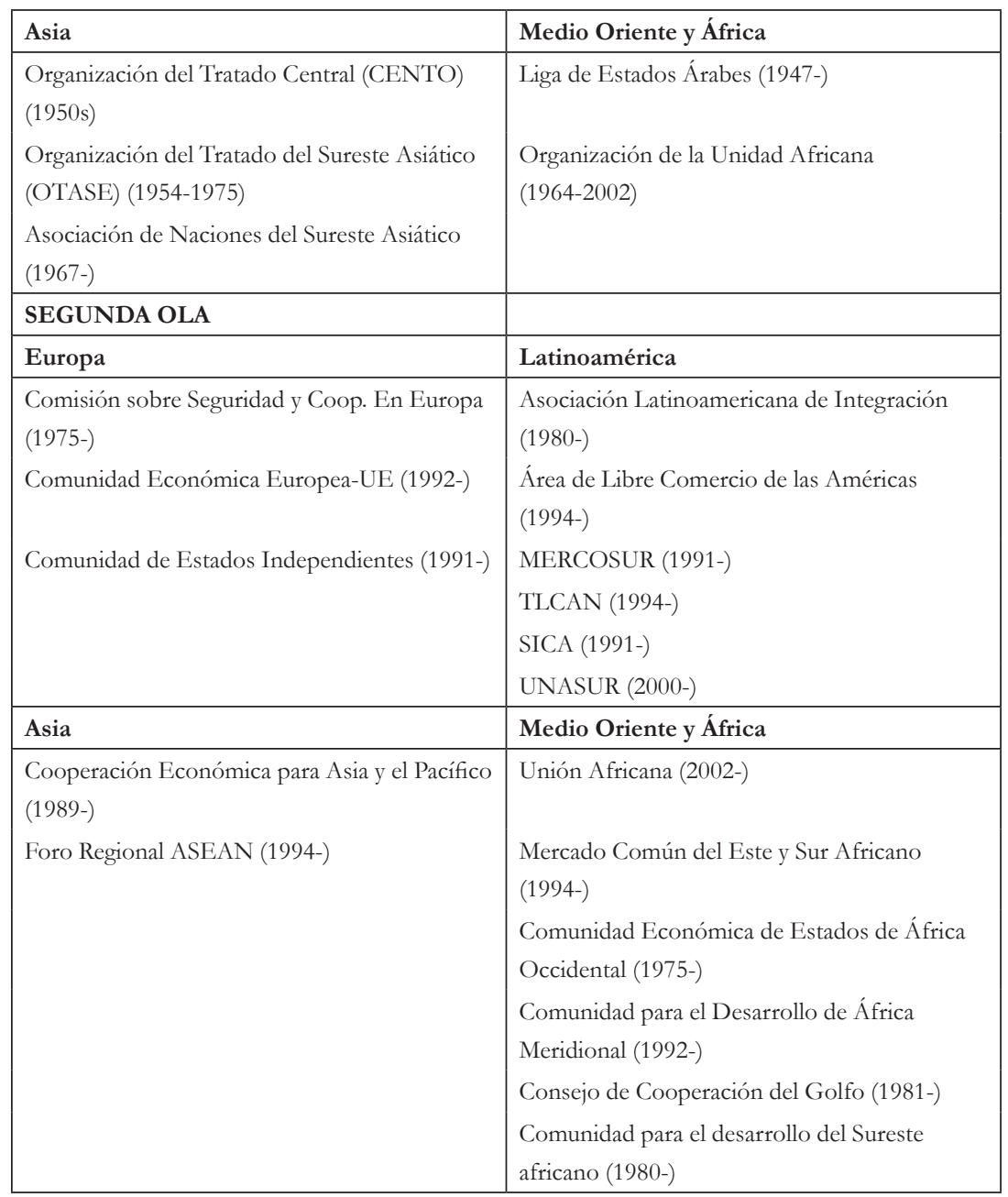

Fuente: elaboración propia, con información de Karns y Mingst (2004).

La visión geoeconómica, que inicia principalmente en los años noventa, se relaciona con estas dinámicas regionales. Desde una perspectiva estructural de la distribución de poder y las estrategias de los Estados, Lee (citada en Gagné, 2007) destaca que la visión del orden regional explora la influencia del dinamismo económico regional sobre la estructura de poder regional y patrones de interacciones estatales, otorgando importancia a los movimientos de flujos, ya sea de personas, bienes, servicios, conocimiento y capital entre territorios en un determinado periodo de tiempo. 
Partiendo de una visión económica, Ohmae (2005) distingue a la regiónEstado, no como una unidad política, sino como una unidad económica, esto es como un actor económico, en donde la economía está imponiendo nuevas escalas de valores en la organización geopolítica.

Así, existen factores políticos y económicos que conllevan al desarrollo de las dinámicas del regionalismo.

Tabla 4. Factores políticos y económicos del Regionalismo

\begin{tabular}{|l|l|}
\hline Factores políticos & Factores económicos \\
\hline Identidad & Altos niveles de interdependencia económica. \\
\hline Amenazas internas y externas & Flujos Comerciales. \\
\hline \multirow{2}{*}{ Liderazgo } & Complementariedad de las economías y políticas. \\
\cline { 2 - 2 } & $\begin{array}{l}\text { Deseo de atraer inversión extranjera a través de la } \\
\text { creación de un mercado más amplio. }\end{array}$ \\
\hline
\end{tabular}

Fuente: elaboración propia con información de Karns y Mingst (2004).

Desde la perspectiva de los factores económicos del regionalismo, la geoeconomía analiza los distintos impactos de las políticas económicas de los Estados, y el impacto de los factores estructurales, cíclicos y situacionales tanto en el nivel regional como internacional (Gagné, 2007). De acuerdo con Coe, Hess, Yeung, Dicken y Henderson (2004), se pueden destacar dos visiones mediante las cuales se ha tratado de ligar las dinámicas de la globalización con las nociones del desarrollo regional. Por un lado, una visión que enfatiza la importancia de las estructuras institucionales endógenas y su capacidad para sostener a las redes globales. La segunda, se enfoca a las redes entre empresas y de materia prima global (Cadenas Globales de Materias Primas) y cadenas de valor (Cadenas Globales de Valor), considerando así un conjunto de factores, como las estructuras organizacionales de las empresas globales, sus sistemas de producción y cómo es el proceso por medio del cual ciertas regiones particulares se adhieren a estas redes, causando diversos impactos en la modernización industrial.

Desde esta perspectiva, se considera una conceptualización sobre desarrollo regional como "un resultado dinámico de interacciones 
complejas entre redes relacionales dentro de un territorio y las redes de producción global, dentro de un contexto de estructuras de gobernanza regional cambiante". (Coe et al., 2004, p. 469).

Partiendo de esta concepción, se puede distinguir que no solo la estructura institucional dentro del mismo territorio es la que impacta en el desarrollo regional de un territorio determinado, sino también una serie de actores que se relacionan y realizan procesos dinámicos con distintas redes de producción de alcance global dentro de una región, distinguiendo que la complejidad reside en el propio dinamismo de las interacciones y procesos como entre las estructuras institucionales cambiantes.

Figura 1. Relación entre el desarrollo regional y las redes de producción global

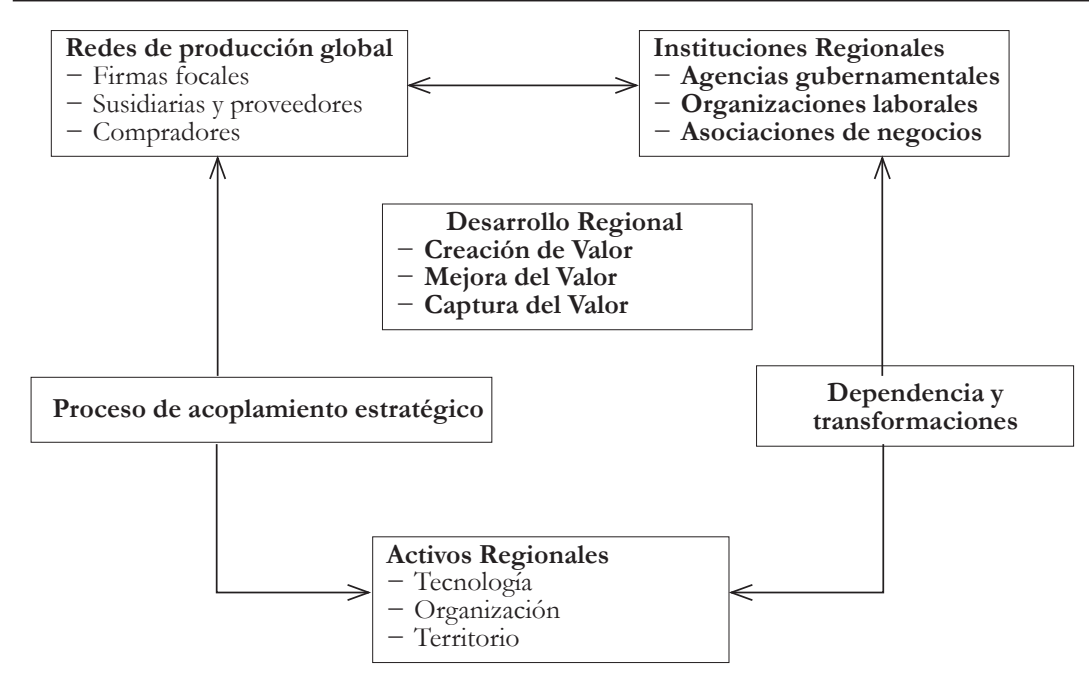

Fuente: Coe, Hess, Yeung, Dicken y Henderson, 2004.

Desde este análisis, se puede identificar que se trata de un ciclo relacional lleno de procesos de cooperación y colaboración, que impactan y se realizan desde dentro de cada una de las escalas y actores hacia fuera, creando dinámicas en las que intervienen tres grandes “ejes", para dar origen al desarrollo regional: las redes globales de producción, las instituciones "regionales" (no necesariamente dentro del mismo 
territorio) y los activos regionales. Es a través de estos tres grandes ejes, que se pueden dar estas transformaciones y procesos de "adaptación" hacia el territorio, aportando mediante estas interacciones y relaciones a través del tiempo una creación, mejora y captura del valor, que aportarán un mejor desarrollo regional.

En este sentido, el término de valor se puede interpretar, de acuerdo con Coe, Hess, Yeung, Dicken y Henderson (2004), desde diferentes tipos o formas de renta económica, que puede obtenerse a través de transacciones comerciales y no comerciales, así como a través del intercambio.

De ahí que las instituciones regionales sean dimensiones mediante las cuales se procesa el ciclo para alcanzar un mejor desarrollo regional, estableciendo distintas estrategias para que fluyan las interacciones y procesos con las otras dimensiones, siendo el principal reto la creación, mejora y captura del valor dentro de los actores que interactúan en un territorio de alcance regional.

\section{El regionalismo en América Latina y el Caribe: la Alianza del Pacífico y la ALADI}

No todos los intentos de regionalismo han sido exitosos. El éxito o el fracaso relativo del regionalismo, como la gobernanza en general, descansa en la evaluación del grado en el que sus objetivos fueron alcanzados y en el manejo y solución de sus problemáticas (Karns y Mingst, 2004). Como se identificó, las transacciones comerciales y el intercambio son una forma en la que se puede crear, mejorar y capturar el valor para lograr un mejor desarrollo en una determinada región.

En la región de América Latina, la visión del desarrollo regional a través del regionalismo fue una de las estrategias que sentó sus bases en los años sesenta. De acuerdo con Chairez (2014), a principios de los años ochenta se llevó a cabo un replanteamiento del Estado, enfrentándose la visión del neoliberalismo económico frente a la lucha ideológica que caracterizó la etapa de la Guerra Fría, trasladándose ahora la lucha al 
terreno de la competencia comercial, lo que produce un cambio de paradigma que va de lo político-ideológico a lo económico-comercial, marcando un camino hacia la regionalización del comercio mundial.

Además, dentro de un mundo globalizado, el regionalismo fue estrategia para evitar el aislamiento o marginalización de los Estados. Desde la esfera económica, el triunfo de las teorías económicas liberales del mercado alentó la eliminación de barreras comerciales y la creación de mercados más grandes, a través de acuerdos comerciales regionales, con la esperanza de imitar el fuerte crecimiento económico que se estaba dando en Europa y Norteamérica (Karns \& Mingst, 2004).

En la región de América latina y el Caribe, Rojas (2013) distingue cuatro etapas temporales del regionalismo, en las que se desarrollan procesos económico-comerciales y de concertación política. Para Prado y Velázquez (2016), son tres las principales etapas de regionalismo en América Latina y el Caribe.

Primera etapa. Regionalismo voluntarista (1960-1980). Se distingue principalmente por el contexto de la Guerra Fría. Se desarrollaron e implementaron políticas de sustitución de importaciones y de imposición de barreras proteccionistas y el crecimiento estaba enfocado hacia adentro. El Estado era considerado el actor preponderante (Rojas, 2013). En este periodo, los países latinoamericanos promovieron algunos acuerdos hacia la integración económica, que se distinguían por sus características restrictivas a ciertos productos. La Asociación Latinoamericana de libre Comercio de 1960 y la Asociación Latinoamericana de Integración son ejemplos de este periodo (Prado \& Velázquez, 2016). Conforme a Prado y Velázquez (2016), la primera etapa se denomina "viejo regionalismo", y comprende el periodo que va desde años sesenta hasta mediados de los años ochenta.

Segunda etapa. Viejo regionalismo. Comprende el periodo entre 1980-1990. El neoliberalismo cobra importancia, a través de una eliminación de barreras arancelarias y la liberalización comercial. Dentro del contexto político latinoamericano, la mayoría de países se encontraban bajo gobiernos militares y autoritarios, además, estaba 
en curso la guerra en Centroamérica, por lo que los procesos de integración regional decayeron. (Rojas, 2013). En contraste, Prado y Velázquez (2016, p. 210), señalan que la segunda etapa se denominó "nuevo regionalismo" o "regionalismo abierto", y comprendió la etapa de mediados de los años ochenta a finales de los años noventa, basado principalmente en postulados del Consenso de Washington y en donde los Tratados de Libre Comercio son las dinámicas principales en la región.

Tercera etapa. Nuevo regionalismo. De acuerdo con Rojas (2013, p. 162), se desarrolla dentro del periodo comprendido entre 1989 y 2005. Las dinámicas de esta etapa, se caracterizan principalmente por el fin de la Guerra Fría y el inicio de un periodo de apertura global, en términos de flujos de mercancías y financieros. Se reconoce la importancia de nuevos actores, como empresas y organismos de sociedad civil. En la región, se constituyeron varios mecanismos de cooperación económica como el Mercado Común del Sur (MERCOSUR) y el Tratado de libre comercio de América del Norte (TLCAN), entre otros. Sin embargo, en el 2005, con la crisis de la Asociación Latinoamericana de Libre Comercio (ALCA), marcó un cambio en el contexto político de $\mathrm{ALyC}$, reflejándose en un incremento de autonomía de los países hacia Estados Unidos, así como un rechazo a las políticas neoliberales.

Para Prado y Velázquez (2016, p. 210), el periodo que inicia a finales de los años noventa hasta la actualidad comprende la tercera fase del regionalismo, denominado como "regionalismo posliberal". En esta fase destacan que el comercio es importante, pero además ofrece nuevas estrategias al "liberalismo abierto", promoviendo en el modelo esquemas de coordinación política novedosos, como la Unión de Naciones del Sur (UNASUR), la Comunidad de Estados Latinoamericanos y del Caribe (CELAC). Conforme a las etapas de regionalismo que distingue Rojas (2013, p. 162-163) para ALyC, la última corresponde al "regionalismo posliberal, pos-hegemónico", que comprende del 2005 a la actualidad. 
En cuanto a los mecanismos de cooperación económica regionales del presente trabajo, se distingue que la ALADI, representa un esquema que se ubica dentro de la primera etapa de regionalismo en América Latina, conocido según Rojas (2013) como "regionalismo voluntarista”, mientras que para Prado y Velázquez (2016), se ubica en la fase de "viejo regionalismo". En cuanto a la AP, se ubica que corresponde a un esquema dentro de la cuarta y última etapa del regionalismo para Rojas (2013) denominada "regionalismo posliberal, pos-hegemónico”, mientras que para Prado y Velázquez (2016) también se ubica en la última fase del regionalismo conocido como "regionalismo posliberal".

Desde su conformación en 2011, la Alianza del Pacífico (AP) —con influencia en la región de ALyC, y conformada por Perú, México, Chile y Colombia - como mecanismo de cooperación económica regional, pretende influir a nivel internacional, pero con especial énfasis en la región de Asia-Pacífico. Además, se perfila como uno de los esquemas más innovadores de integración comercial y económica debido al tipo de objetivos que persigue, que consisten en construir un área de integración profunda de manera progresiva hacia la libre circulación de bienes, servicios, capitales y personas; impulsar un mayor crecimiento, desarrollo y competitividad de las economías de las partes; convertirse en una plataforma de articulación política, integración económica y comercial y proyección al mundo, con énfasis en la región Asia-Pacífico (Alianza del Pacifico, 2014).

Por su parte, la Asociación Latinoamericana de Integración (ALADI) tuvo sus orígenes en 1980 y está conformada por trece países miembros: Argentina, Bolivia, Brasil, Chile, Colombia, Cuba, Ecuador, México, Panamá, Paraguay, Perú, Uruguay y Venezuela, que representan en su conjunto 20 millones de kilómetros cuadrados y más de 510 millones de habitantes (ALADI, 2015, sn). La ALADI tiene como principios generales: pluralismo en materia política y económica; convergencia progresiva de acciones parciales hacia la formación de un mercado común latinoamericano; flexibilidad; tratamientos diferenciales en base al nivel de desarrollo de los países miembros, y multiplicidad en las formas de 
concertación de instrumentos comerciales. La ALADI propicia la creación de un área de preferencias económicas en la región, con el objetivo final de lograr un mercado común latinoamericano.

En este contexto, Andrew Axline (citado por Hettne, 2005, p. 545) señala que la cooperación regional puede ser únicamente entendida desde la perspectiva del interés nacional de cada uno de los Estados miembros, en donde la política de las negociaciones regionales manejará el interés de todos los miembros, a diferencia del término de integración regional. Por su parte Hettne (2005) distingue que la regionalización se refiere a procesos más complejos en la formación de regiones, ya sea si estas son construidas conscientemente o causadas a través de procesos espontáneos. Por ello, se identifican principalmente, cuatro dimensiones del regionalismo.

1) Bloques comerciales: las negociaciones comerciales regionales son vistas como la segunda mejor opción, y por lo tanto son juzgados conforme a lo que contribuyen hacia un sistema comercial más cerrado o hacia un sistema multilateral abierto (Hettnet, 2005).

2) Regionalismo monetario: el asunto monetario ha sido descuidado, dedido a la crecienteimportancia de los acuerdos o negociaciones comerciales dentro del discurso regionalista. El regionalismo monetario puede tener muchos objetivos; sin embargo, el más importante es la estabilidad financiera, que significa una ausencia de movilidad excesiva. Toda vez que las crisis financieras tienen el potencial de expandirse a lo largo de los países, requiere una respuesta de caracter colectivo (Hettnet, 2005).

3) Regionalismo para el desarrollo: principalmente comprende el concertar esfuerzos de un grupo de países dentro de una misma región geográfica para ampliar la complementariedad de las unidades políticas que lo constituyen, así como las capacidades de la economía regional en su conjunto, ya sea a través de acuerdos, o a través de estrategias regionales más complejas (Hettnet, 2005). Además, el desarrollo es entendido como un fenómeno multidimensional, que 
depende de los efectos positivos y los vínculos entre los diferentes sectores de una economía y la sociedad.

4) Regionalismo de seguridad: a pesar de que la primera generación de integración regional se enfocó inicialmente en la economía, también se consideran ejes importantes la paz y la seguridad. Desde una perspectiva teórica, las preocupaciones por la seguridad son interpretadas como factores causales para obligar a los Estados a cooperar por el riesgo de que el conflicto se regionalice.

\section{Metodología}

El trabajo realiza un análisis comparativo de las bases de datos del Banco Mundial 2016, para el periodo comprendido entre 2005 y 2014, de las importaciones (Banco Mundial, 2016b), exportaciones (Banco Mundial, 2016a)y los saldos de la balanza comercial, para cada uno de los países que integran la AP, la ALADI, y ALyC, para con ello determinar su aportación en términos comerciales, frente a la región. Asimismo, se comparan los datos con el total mundial de exportaciones e importaciones para el periodo 2005-2014, a fin de identificar la perspectiva de valor, conforme a sus transacciones comerciales, entendidas las exportaciones de bienes y servicios, como todas las transacciones entre los residentes de un país y el resto del mundo, que implican una transferencia de propiedad de los residentes a no residentes sobre mercancías generales, bienes enviados a procesamiento y reparación, oro no monetario y servicios, conforme lo considera el Banco Mundial (2016a). Teniendo en cuenta lo anterior, se consideraron las bases de datos del Banco Mundial (2016b) de las importaciones de bienes y servicios que comprenden todas las transacciones entre residentes de un país y el resto del mundo, lo que implica una transferencia de propiedad de los no residentes a los residentes sobre mercancías generales, bienes enviados a procesamiento y reparación, oro no monetario y servicios. Los datos tanto de las exportaciones, importaciones y de saldos de la balanza comercial, se contemplan en dólares, a precios actuales. Finalmente se presenta una caracterización de la red de relaciones económicas comerciales que sostienen cada uno de los países que pertenecen a la AP y la ALADI, 
utilizando como herramienta el software UCINET 6 y caracterizando solo las relaciones dentro de la red.

\section{Análisis y Resultados}

En la tabla 5 se muestran las dinámicas de las exportaciones, importaciones y el saldo de la balanza comercial para la AP, la ALADI y $\mathrm{ALyC}$, frente al total mundial de exportaciones e importaciones.

En cuanto a las dinámicas que se reflejan para la AP, se puede identificar un saldo negativo de la balanza comercial para los países que conforman en su conjunto la AP, para los años: 2005, 2008, 2011, 2012, 2013 y 2014, que va incrementando a partir de 2011. En cuanto a sus porcentajes de exportaciones e importaciones, y en comparación con el total de ALyC, hasta 2011 el porcentaje de sus importaciones es mayor al de sus exportaciones (véase tabla 6). En este aspecto, a partir del 2012 se observa una tendencia a la inversa, representando un porcentaje mayor de sus exportaciones en comparación con el total de ALyC. En relación con el total mundial, la AP refleja que en la mayor parte del periodo de análisis sus exportaciones representaron un porcentaje menor al de sus importaciones (véase tabla 7). Este dato es importante para las dinámicas desde una visión del total mundial, pues el porcentaje es muy representativo, considerando que solo conforman 4 países este mecanismo de cooperación económica dentro de la región de ALyC.

En cuanto a las dinámicas de la ALADI, hay que considerar que son 13 los países que la conforman y sus resultados reflejan el total de las exportaciones, importaciones y saldos de la balanza comercial de los países que la conforman, reflejadas en la tabla 5 . En cuanto al análisis, se observa que a partir de 2012 el saldo de la balanza comercial es negativo, con una tendencia a la alza. En cuanto a los porcentajes de exportaciones e importaciones, y en comparación con el total de ALyC, durante el periodo de análisis las exportaciones han sido mayores con respecto a sus importaciones desde 2005 a 2013, pues en 2014 las importaciones reflejan un porcentaje mayor a las exportaciones en 
comparación con las dinámicas regionales. En cuanto al análisis de las dinámicas con respecto al total mundial, las exportaciones en la ALADI en solo seis años han representado un porcentaje mayor en comparación con sus importaciones; sin embargo, hay que destacar que en los últimos tres años contados a partir del 2012, es cuando se identifica una disminución en el porcentaje de sus exportaciones en comparación con sus importaciones, en relación con el total mundial.

Para las dinámicas de la región de ALyC, se observa conforme a la tabla 5, que el saldo de la balanza comercial empieza una tendencia negativa a partir del 2012, la cual aumenta dentro de los últimos tres años de análisis. Con respecto a la tabla 7 , se identifica que en los primeros tres años de análisis (2005, 2006 y 2007), las exportaciones de la región son mayores a las importaciones con respecto a las dinámicas de los totales mundiales. Sin embargo, a partir del 2008, las importaciones comienzan a representar un porcentaje mayor al de las exportaciones con respecto al total mundial. En cuanto al comportamiento del total mundial de exportaciones e importaciones, se puede observar en la tabla 5, que durante el periodo de análisis, las exportaciones han sido mayores a las importaciones.

El número de relaciones económicas comerciales de cada país que conforma cada uno de estos mecanismos también es importante, pues forma parte del ciclo para mejorar el desarrollo regional. En la figura 2 se pueden identificar los países con los que mantienen relaciones económicas comerciales los países miembros de la AP y la ALADI de manera individual, conjunta, o como mecanismos de cooperación económica, en los que sobresale Chile, que es el país mejor posicionado por el número de relaciones dentro de los países que conforman el análisis. 
Tabla 5. Comparativo de exportaciones, importaciones y saldo balanza comercial de los mecanismos regionales AP, ALADI y total de ALyC frente a las exportaciones e importaciones del total mundial 2005-2014 (dólares americanos a precios actuales)

\begin{tabular}{|c|c|c|c|c|c|c|}
\hline & & 2005 & 2006 & 2007 & 2008 & 2009 \\
\hline \multirow{3}{*}{ 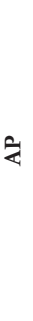 } & Exportaciones & $322,854,853,047.77$ & $387,780,066,238.61$ & $431,926,327,720.27$ & $463,999,630,707.28$ & $377,714,604,982.78$ \\
\hline & Importaciones & $323,689,912,250.10$ & $373,361,597,629.29$ & $423,042,594,432.69$ & $483,874,174,619.10$ & $375,584,513,994.76$ \\
\hline & $\begin{array}{l}\text { Saldo balanza } \\
\text { comercial }\end{array}$ & $(835,059,202.33)$ & $14,418,468,609.33$ & $8,883,733,287.58$ & $(19,874,543,911.81)$ & $2,130,090,988.03$ \\
\hline \multirow{3}{*}{ 尝 } & Exportaciones & $595,327,589,343.92$ & $708,727,767,705.64$ & $804,522,767,230.07$ & $935,436,711,898.22$ & $740,498,933,627.93$ \\
\hline & Importaciones & $\begin{array}{l}\cdots \cdots \cdots \cdots \cdots \cdots \\
518,581,187,829.62\end{array}$ & $613,576,900,498.93$ & $739,368,636,528.04$ & $900,627,197,736.72$ & $706,661,497,605.40$ \\
\hline & $\begin{array}{l}\text { Saldo balanza } \\
\text { comercial }\end{array}$ & $\begin{array}{l}\ldots \ldots \ldots \ldots \ldots \\
76,746,401,514.29\end{array}$ & $95,150,867,206.70$ & $65,154,130,702.03$ & $34,809,514,161.51$ & $33,837,436,022.53$ \\
\hline \multirow{3}{*}{ 突 } & Exportaciones & $734,821,763,298.27$ & $872,736,455,736.18$ & $987,471,703,101.65$ & $1,145,958,108,200.29$ & $906,357,155,935.28$ \\
\hline & Importaciones & $657,304,956,386.85$ & $775,305,525,045.10$ & $929,791,102,798.74$ & $1,126,055,644,849.54$ & $880,703,982,599.21$ \\
\hline & $\begin{array}{l}\text { Saldo balanza } \\
\text { comercial }\end{array}$ & $77,516,806,911.41$ & $97,430,930,691.08$ & $57,680,600,302.91$ & $19,902,463,350.75$ & $25,653,173,336.08$ \\
\hline \multirow{2}{*}{ 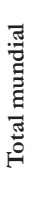 } & Exportaciones & $12,868,598,396,406.40$ & $\begin{array}{l}\cdots \cdots \cdots \cdots \cdots \\
14,799,645,725,889.10\end{array}$ & $\begin{array}{l}\cdots \cdots \cdots \cdots \cdots \\
17,239,697,066,719.00\end{array}$ & $19,777,124,492,856.30$ & $15,803,073,484,442.70$ \\
\hline & Importaciones & $12,656,727,200,241.80$ & $\begin{array}{l}\cdots \cdots \cdots \cdots \cdots \cdots \\
14,474,010,520,625.80\end{array}$ & $\begin{array}{l}\cdots \cdots \cdots \cdots \cdots \\
16,743,778,073,051.50\end{array}$ & $19,346,230,747,712.90$ & $15,321,641,447,103.50$ \\
\hline
\end{tabular}

Continúa

Fuente: elaboración propia con datos del Banco Mundial (2016a y 2016b).

- Para datos de las exportaciones. Se consideraron las exportaciones de bienes y servicios, que comprenden todas las transacciones entre los residentes de un país y el resto del mundo, y que implican una transferencia de propiedad de los residentes a los no residentes sobre mercancías generales, bienes enviados a procesamiento y reparación, oro no monetario y servicios. Para más información, consultar http://datos.bancomundial.org/indicador/BX.GSR.GNFS.CD

- Para datos de las importaciones. Se consideraron las importaciones de bienes y servicios, que comprenden todas las transacciones entre residentes de un país y el resto del mundo, y que implican una transferencia de propiedad de los no residentes a los residentes sobre mercancías generales, bienes enviados a procesamiento y reparación, oro no monetario y servicios. Para más información, consultar http://datos.bancomundial.org/indicador/BM.GSR.GNFS.CD 


\begin{tabular}{|c|c|c|c|c|}
\hline 2010 & 2011 & 2012 & 2013 & 2014 \\
\hline $481,064,415,272.42$ & $573,968,644,621.07$ & $\begin{array}{l}\ldots \ldots \ldots \ldots \ldots \\
597,390,716,109.23\end{array}$ & $605,017,683,044.35$ & $614,536,168,508.78$ \\
\hline $478,197,514,446.19$ & $574,064,983,415.09$ & 608,516,846,158.73 & $622,443,940,247.76$ & 639,882,119,280.21 \\
\hline $2,866,900,826.23$ & $(96,338,794.02)$ & $\begin{array}{l}(11,126,130,049.50) \\
\text { (n) }\end{array}$ & $(17,426,257,203.41)$ & $(25,345,950,771.44)$ \\
\hline $931,152,357,055.70$ & $\begin{array}{l}\cdots \cdots \cdots \cdots \cdots \\
1,147,577,856,821.37\end{array}$ & $\begin{array}{l}\cdots \cdots \cdots \cdots \cdots \\
1,167,255,174,220.73\end{array}$ & $1,169,240,128,357.70$ & $\begin{array}{l}\ldots \ldots \ldots \ldots \ldots \\
1,060,981,231,075.95\end{array}$ \\
\hline $911,678,632,502.61$ & $\begin{array}{l}\ldots \ldots \ldots \ldots \ldots \\
1,116,869,839,721.79\end{array}$ & $\begin{array}{l}\ldots \ldots \ldots \ldots \ldots \\
1,167,369,901,851.69\end{array}$ & $1,207,578,773,259.47$ & $\begin{array}{l}\ldots \ldots \ldots \ldots \ldots \\
1,137,109,281,127.38\end{array}$ \\
\hline $19,473,724,553.09$ & $30,708,017,099.57$ & $(114,727,630.96)$ & $(38,338,644,901.77)$ & $(76,128,050,051.43)$ \\
\hline $1,132,643,261,540.50$ & $\begin{array}{l}\cdots \ldots \ldots \ldots \ldots \\
1,401,942,571,954.67\end{array}$ & $\begin{array}{l}\cdots \cdots \cdots \cdots \cdots \\
1,424,764,289,017.01\end{array}$ & $1,426,754,418,382.29$ & $\begin{array}{l}\ldots \ldots \ldots \ldots \ldots \\
1,410,290,670,692.27\end{array}$ \\
\hline $1,124,921,650,950.73$ & $\begin{array}{l}\ldots \ldots \ldots \ldots \ldots \\
1,383,466,417,766.17\end{array}$ & $\begin{array}{l}\cdots \ldots \ldots \ldots \ldots \\
1,440,722,984,629.83\end{array}$ & $1,485,630,110,773.92$ & $\begin{array}{l}\ldots \ldots \ldots \ldots \ldots \\
1,491,192,937,692.78\end{array}$ \\
\hline $7,721,610,589.77$ & $18,476,154,188.50$ & $(15,958,695,612.82)$ & $(58,875,692,391.63)$ & $(80,902,267,000.51)$ \\
\hline $18,760,112,417,962.40$ & $22,270,577,995,916.50$ & $22,559,984,957,033.60$ & $23,269,708,367,101.10$ & $23,665,982,490,484.80$ \\
\hline $18,231,434,436,727.80$ & $\begin{array}{l}\cdots \cdots \cdots \cdots \cdots \\
21,707,975,540,685.80\end{array}$ & $21,941,725,029,304.80$ & $22,531,789,636,104.30$ & $\begin{array}{l}\ldots \ldots \ldots \ldots \ldots \\
22,911,191,482,843.60\end{array}$ \\
\hline
\end{tabular}


Tabla 6. Porcentaje de importaciones y exportaciones de la AP y ALADI en comparación con el total de ALyC

\begin{tabular}{|l|l|l|l|l|l|l|l|l|l|l|l|}
\hline Mecanismo & & 2005 & 2006 & 2007 & 2008 & 2009 & 2010 & 2011 & 2012 & 2013 & 2014 \\
\hline \multirow{2}{*}{$\begin{array}{l}\text { Alianza del } \\
\text { Pacífico }\end{array}$} & Exportación & 43.94 & 44.43 & 43.74 & 40.49 & 41.67 & 42.47 & 40.94 & 41.93 & 42.41 & 43.58 \\
\cline { 2 - 11 } & Importación & 49.25 & 48.16 & 45.50 & 42.97 & 42.65 & 42.51 & 41.49 & 42.24 & 41.90 & 42.91 \\
\hline \multirow{2}{*}{ ALADI } & Exportación & 81.02 & 81.21 & 81.47 & 81.63 & 81.70 & 82.21 & 81.86 & 81.93 & 81.95 & 75.23 \\
\cline { 2 - 11 } & Importación & 78.90 & 79.14 & 79.52 & 79.98 & 80.24 & 81.04 & 80.73 & 81.03 & 81.28 & 76.26 \\
\hline
\end{tabular}

Fuente: elaboración propia con datos del Banco Mundial (2016a y 2016b).

Tabla 7. Porcentaje comparativo del total de las exportaciones e importaciones de la AP, ALADI y ALyC en relación con el total mundial 2005-2014

\begin{tabular}{|l|l|c|c|c|c|c|c|c|c|c|c|}
\hline & & $\begin{array}{c}2005 \\
\%\end{array}$ & $\begin{array}{c}2006 \\
\%\end{array}$ & $\begin{array}{c}2007 \\
\%\end{array}$ & $\begin{array}{c}2008 \\
\%\end{array}$ & $\begin{array}{c}2009 \\
\%\end{array}$ & $\begin{array}{c}2010 \\
\%\end{array}$ & $\begin{array}{c}2011 \\
\%\end{array}$ & $\begin{array}{c}2012 \\
\%\end{array}$ & $\begin{array}{c}2013 \\
\%\end{array}$ & $\begin{array}{c}2014 \\
\%\end{array}$ \\
\hline $\begin{array}{l}\text { Alianza del } \\
\text { Pacífico }\end{array}$ & Exportación & 2.51 & 2.62 & 2.51 & 2.35 & 2.39 & 2.56 & 2.58 & 2.65 & 2.60 & 2.60 \\
\cline { 2 - 13 } & Importación & 2.56 & 2.58 & 2.53 & 2.50 & 2.45 & 2.62 & 2.64 & 2.77 & 2.76 & 2.79 \\
\hline \multirow{4}{*}{ ALADI } & Exportación & 4.63 & 4.79 & 4.67 & 4.73 & 4.69 & 4.96 & 5.15 & 5.17 & 5.02 & 4.48 \\
\cline { 2 - 12 } $\begin{array}{l}\text { Ampórica } \\
\text { Latina y el } \\
\text { Caribe }\end{array}$ & Exportación & 4.10 & 4.24 & 4.42 & 4.66 & 4.61 & 5.00 & 5.14 & 5.32 & 5.36 & 4.96 \\
\cline { 2 - 12 } & Importación & 5.19 & 5.36 & 5.55 & 5.82 & 5.75 & 6.17 & 6.37 & 6.57 & 6.59 & 6.51 \\
\hline
\end{tabular}

Fuente: elaboración propia con datos del Banco Mundial (2016a y 2016b). 
Figura 2. Red de relaciones económicas comerciales de los países de la Alianza del Pacífico y ALADI

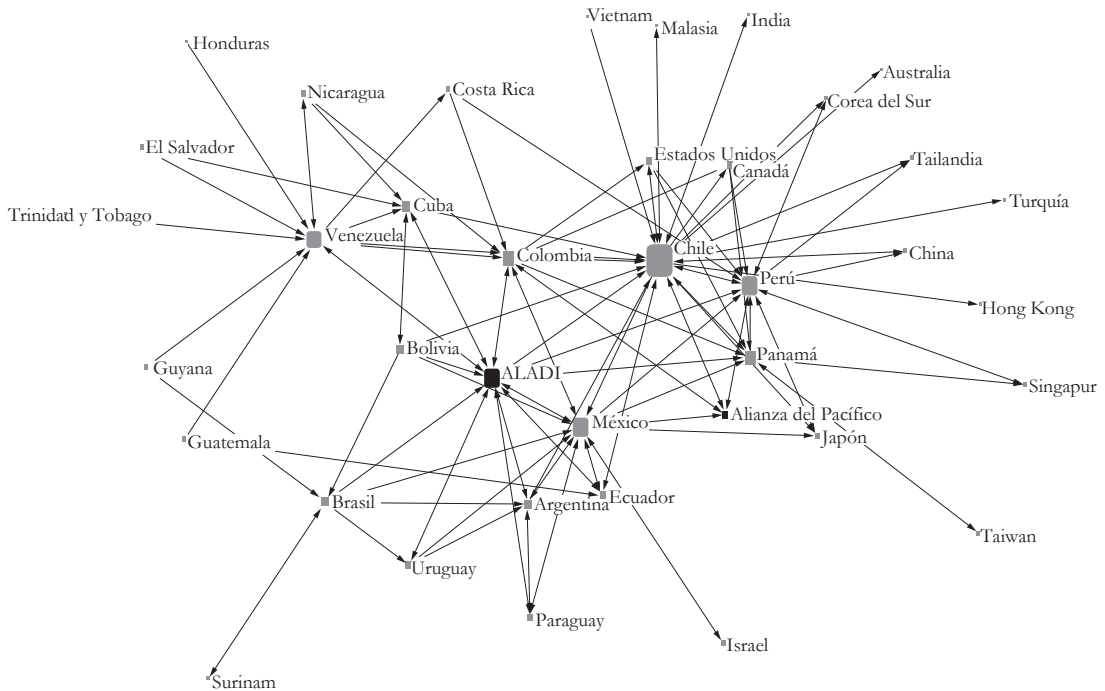

Fuente: elaboración propia con software UCINET 6 con resultados de Borgatti, Everett y Freeman, 2002.

\section{Reflexiones Finales}

Las dinámicas y procesos dentro del sistema internacional y sus actores continúan en evolución constante. Los organismos internacionales siguen siendo los principales encargados del diseño de las dinámicas y políticas internacionales de la cooperación internacional para el desarrollo (CID). Además, como agentes institucionalizadores del desarrollo a nivel global, han enfrentado varios retos, evolucionando con ello sus perspectivas conforme a las nuevas problemáticas.

A través del tiempo, se han reflejado los esfuerzos no solo a nivel global, sino en la escala regional, buscando distintas estrategias para la lograr el desarrollo regional, como un espacio más flexible y dinámico. En cuanto a la región de América latina y el Caribe, considerada como una de las regiones más dinámicas, los esquemas de cooperación económica no han tenido éxitos hacia una verdadera integración regional. Parte de esta problemática reside precisamente en la variación del grado de institucionalización de estos múltiples mecanismos de cooperación. 
La búsqueda de valor es otro gran reto adicional al de la creación, mejora y captura de valor, pues tiene que ver con cuestiones de innovación. Los mecanismos de cooperación económica como la AP y la ALADI representan grandes oportunidades para aportar al desarrollo tanto regional como global. El reto del primero, principalmente, consiste en establecer estrategias reales para conectarse y adaptarse a los tres grandes ejes del ciclo del desarrollo en la región de Asia-Pacífico, como dentro de la región de ALyC. En cuanto a la ALADI, las distintas visiones del contexto de la economía global entre los propios miembros han llevado a que pierda su dinamismo como mecanismo que conduzca a una verdadera integración. Lo anterior, aunado a las distintas visiones ideológicas y políticas entre los miembros de la ALADI, ha conducido a que entre los propios miembros busquen y den origen a nuevas estrategias de inserción a la cooperación económica y comercial de las dinámicas globales, caracterizadas por ser cambiantes y competitivas, y a las que cada vez más se suman nuevos actores y procesos.

\section{Referencias}

ALADI (2015). Quienes somos. Recuperado de http:/ / www.aladi.org/sitioAladi/quienesSomos.html

Alianza del Pacífico (2014). Abecé. Alianza del Pacifico. Recuperado de http:// alianzapacifico.net/documents/2014/ABC_ALIANZA_PACIFICO_2014.pdf

Álvarez, S. (2012). Una Introducción a la cooperación internacional al desarrollo. REDUR, (10), 285-309. Recuperado dehttp://www.unirioja. es/dptos/dd/redur/numero10/alvarez.pdf

Banco Mundial (2016a). Exportaciones. Recuperado de http://datos.bancomundial.org/indicador/BX.GSR.GNFS.CD

Banco Mundial (2016b). Importaciones. Recuperado de http://datos.bancomundial.org/indicador/BM.GSR.GNFS.CD

Borgatti, S.P., Everett, M.G., \& Freeman, L.C. (2002). Ucinet for Windows: Software for Social Network. Analysis. Harvard, MA: Analytic Technologies. Bremer, J. (2010). Tiempos de Guerra y Paz. Los pilares de la diplomacia: De Westfalia a San Francisco. México: Taurus. 
Chaires, R.E. (2014). La gobernanza en el sistema politico internacional de la posguerra fría. El tema de la pobreza en México. México: Universidad de Colima.

Coe, N.M., Hess, M., Yeung, H.W., Dicken, P., \& Henderson, J. (2004). Globalizing Regional Development: A Global Production Networks Perspective. Transactions of the Institute of British Geographers, 29(4), 468484. Recuperado de https:/ / is.cuni.cz/studium/eng/predmety/index. php?do $=$ download \&did $=41345 \& \mathrm{kod}=\mathrm{MZ340P} 45$

Gasper, D. (2005). The Ethics of Development. Edinburgh: University Press. Hettne, B. (2005). Beyond the New Regionalism. New Political Economy. 10(4), 543-571. Recuperado de http://media.library.ku.edu.tr/reserve/resspring08/intl532_MGEC632_Zonis/3_New_Regionalism_in_Comparative_Perspective.pdf

Hurrell, A. (2007). One World? Many Worlds? The Place of Regions in the Study of International Society. International Affairs 83(I), 127-146. Karns, M., \& Mingst, K. (2004). International Organizations. The politics and processes of global governance. Reino Unido: Lynne Rienner Publishers.

Maira, L. (1997). América Latina en el nuevo escenario internacional. En Instituto Matías Romero, Organismos Hemisféricos y Mecanismos de concertación en América Latina (pp. 125-154). México: SRE.

Observatorio de Multinacionales en América Latina (2012). Consenso de Washington. Recuperado de http://omal.info/IMG/article_PDF/ Consenso-de-Washington_a4820.pdf

OECD (2001). Geographical Distribution of Financial Flows to Developing Countries. Disbursements, Commitments, Country Indicators. París: OECD. Recuperado de http:/ / www.keepeek.com/Digital-Asset-Management/oecd/ development/geographical-distribution-of-financial-flows-to-aidrecipients-2001_fin_flows_aid-2001-en-fr\#page321

OECD (2006). Geographical Distribution of Financial Flows to Developing Countries. Disbursements, Commitments, Country Indicators. París: OECD. Recuperado de http:/ /www.keepeek.com/Digital-Asset-Management/oecd/ development/geographical-distribution-of-financial-flows-to-aidrecipients-2006_fin_flows_aid-2006-en-fr\#page317

OECD (2011). Geographical Distribution of Financial Flows to Developing Countries. Disbursements, Commitments, Country Indicators. París: OECD. Recuperado ede http:/ / www.keepeek.com/Digital-Asset-Management/ oecd/development/geographical-distribution-of-financial-flowsto-developing-countries-2011_fin_flows_dev-2011-en-fr\#page275, 
OECD (2016). Geographical Distribution of Financial Flows to Developing Countries. Disbursements, Commitments, Country Indicators. París: OECD. Recuperado de http://www.keepeek.com/Digital-Asset-Management/oecd/development/geographical-distribution-of-financial-flows-to-developingcountries-2016_fin_flows_dev-2016-en-fr\#page302,

Ohmae, K. (2005). El próximo Escenario global. Desafíos y Oportunidades en un mundo sin fronteras. México: Grupo Editorial Norma.

Phillips, N. (2003). The Rise and Fall of Open Regionalism? Comparative Reflections on Regional Governance in Governance in the Southern Cone of Latin America. Third World Quarterly. 24(2), 217-234. Recuperadode http:/ / alternative-regionalisms.org/wp-content/uploads/2009/07/ phillips_openregionalisminla.pdf

Prado, L.J.P., \& Velázquez, R. (2016). La Alianza del Pacífico: comercio y cooperación al servicio de la integración. Revista Mexicana de Política Exterior, 106 (ene-abril), 205-235.

Red Argentina para la Cooperación Internacional (2012). Manual de Cooperación Internacional. Una herramiento de fortalecimiento para las organizaciones de la sociedad civil (cuarta edición). Recuperado de http:/ / www.raci.org. ar/recursos-para-ong/manual-de-cooperacion-internacional/manualde-cooperacion-internacional-una-herramienta-de-fortalecimientopara-las-organizaciones-de-la-sociedad-civil-osc

Rojas, A. F. (2013). Regionalismo e integración regional. En T. Legler., A. Santa Cruz, \& Zamudio, G. L. (Eds.) Introducción a las Relaciones Internacionales: América Latina y la Política Global (pp. 158-171). México: Oxford. Tezanos, S., \& Martinez, A. (2010). Ayuda oficial al Desarrollo para América Latina y el Caribe en el punto de inflexion del milenio. Revista Problemas del Desarrollo, 162(41), 31-56. Recuperado de http://www. scielo.org.mx/pdf/prode/v41n162/v41n162a3.pdf

Tugores, Q.J. (2005). Economia Internacional. España: Mc Graw Hill.

UN (2016). Secretary-General. Recuperado de http://www.un.org/sustainabledevelopment/secretary-general

UNDP (2016). Looking Forward: People, Planet and Prosperity. Recuperado dehttp://50.undp.org/en/\#timeline

Weiss, T. G., Forsythe, D.P., \& Coate, R.A. (2004). The United Nations and Changing World Politics. USA: Westview Press. 